\title{
A inteligência artificial na educação: utilizações e possibilidades
}

\author{
SIL VEIRA, Antônio Claudio Jorge da ${ }^{1}$ \\ VIEIRA JUNIOR, Niltom ${ }^{2}$
}

\section{RESUMO}

Este trabalho discute o uso das Tecnologias da Informação e Comunicação (TIC), com o foco na Inteligência Artificial (IA) aplicada a sistemas educacionais. As tecnologias atuais já permitem o acesso e a otimização de plataformas disponíveis em todo o mundo e pretende-se, com essa investigação, avaliar os desafios para que essas possibilidades sejam ampliadas. Para complemento deste estudo, são apresentadas instituições internacionais pioneiras na utilização da Inteligência Artificial como plataforma de aprendizagem em larga escala. Trata-se de uma pesquisa qualitativa, com o propósito de auxiliar os gestores educacionais na busca de políticas voltadas para a melhoria do ensino e suas possíveis consequências sociais.

\section{Inteligência Artificial. Educação à Distância. Escola Pública. Metodologia de} Aprendizagem.

\section{The Artificial Intelligence in Education: uses and possibilities}

\section{ABSTRACT}

This work discusses the use of Information and Communication Technologies (ICT), with a focus on Artificial Intelligence (AI) applied to educational systems. Today's technologies already allow access to and optimization of platforms available around the world, and this research intends to assess the challenges for these possibilities to be expanded. To complement this study, we present pioneering international institutions in the use of Artificial Intelligence as a platform for large-scale learning. It is a qualitative research, with the purpose of assisting educational managers in the pursuit of policies aimed at improving education and its possible social consequences.

Artificial Intelligence. Distance Education. Public school. Learning Methodology.

\section{INTRODUÇÃO}

Por meio desta pesquisa, sobre a utilização das Tecnologias Digitais de Informação e Comunicação (TDIC), dando ênfase à Inteligência Artificial, à sua

\footnotetext{
${ }^{1}$ Antônio Claudio Jorge da Silveira. Pós-Graduação em Docência. Instituto Federal de Minas Gerais - Campus Arcos. E-mail: aclaudio.jorge@hotmail.com

${ }^{2}$ Niltom Vieira Junior. Pós-Graduação em Docência. Instituto Federal de Minas Gerais Campus Arcos. E-mail: niltom.vieira@ifmg.edu.br
} 
utilização e aos seus impactos na educação, pretende-se buscar informações sobre a Inteligência Artificial (IA) aplicada à Educação à Distância (EaD).

Vive-se no século XXI o fenômeno da comunicação online, em que a interação se dá a qualquer momento e com qualquer pessoa ou grupo a partir de dispositivos eletrônicos. Bancos, grandes empresas e instituições disponibilizam acesso e serviços digitais os quais facilitam a vida da população. Mesmo assim, de forma conservadora, as instituições educacionais vivem uma dupla realidade, na qual a grande maioria dos estudantes em escolas públicas é excluída dos recursos tecnológicos devido às políticas públicas insuficientes e à realidade precária de infraestrutura física das escolas públicas estaduais e municipais. Por outro lado, os centros e institutos federais, por motivos diversos, apresentam maior emancipação tecnológica e administrativa, as quais proporcionaram a essas instituições, geralmente, melhores condições.

Contudo, a realidade atual de sistemas inteligentes já apresenta capacidade de armazenamento de grandes bases de dados (metadata), que possibilitam acesso a informações diversas com disponibilidade de múltiplos acessos simultâneos por milhares de pessoas. Essas tecnologias, aliadas aos interesses da sociedade e de grandes corporações, permitem o atendimento em massa e abrem diferentes nichos de mercado. Embora muito lentamente, as políticas públicas no Brasil têm caminhado nesse sentido, conforme visto no Decreto 9.057/2017, no qual é proposta a utilização de uma base de dados diversa e instrutores remotos para auxiliar os professores em escolas distribuídas em todo o país (BRASIL, 2017).

Os especialistas em tecnologia da informação, por serem estudiosos do tema, concordam que a substituição dos mentores remotos por sistemas inteligentes (Inteligência Artificial) dependerá de questões sociais. Sendo assim, da mesma forma que se estabeleceu a confiança em realizar um pagamento online, deve haver a confiança dos usuários para utilizar sistemas remotos no sentido educacional. Iniciativas como esta, aplicadas à educação, já começam a se difundir em países, como nos Estados Unidos, na Índia e em alguns países europeus.

\section{A tecnologia da informação na educação}

Os professores e os gestores da educação podem atuar como multiplicadores do conhecimento disponível hoje nas plataformas digitais, como Google, YouTube, Moodle, livrarias eletrônicas e bases de dados online disponíveis, para aplicá-las ao ensino. Já existe muito material, como vídeos, jogos, imagens, animações e textos eletrônicos, os quais deveriam ser disponibilizados aos alunos. Além disso, são criados materiais a todo 0 momento, os quais poderiam trazer dinamismo e facilidade ao professor e ao aluno dentro da sala de aula. Entretanto, por razões diversas - inclusive a falta 
de políticas para formação continuada nesse sentido - nem sempre isso ocorre.

Grandes descobertas no decorrer dos séculos, como o papel, a máquina de escrever, o telescópio e, principalmente, entre os anos 1950 e 1990, a Tecnologia da Informação, possibilitaram avanços sociais. Nesse sentido, a introdução dos primeiros computadores na sociedade, principalmente em grandes empresas como IBM e nas repartições públicas, gerou uma revolução nas relações profissionais e pessoais. Como apontado por Xavier (2013, p. 1):

Não se questiona mais a adoção das tecnologias digitais de informação e comunicação (TDIC) pela educação. Discute-se agora como utilizá-las para auxiliar o professor a trabalhar a diversidade de conteúdos presentes nas disciplinas do currículo escolar.

Especificamente com a Inteligência Artificial não é diferente. Várias aplicações para comunicação remota já são utilizadas há longa data, como aviões não tripulados, máquinas para controle e detecção de objetos, entre outros. Entretanto, sua utilização na educação ainda é insuficiente e indisponível ao grande público.

A pergunta que se pode fazer é: o Estado está utilizando as novas tecnologias já existentes como aliadas efetivas do desenvolvimento profissional, social e cultural? Além da falta de investimentos e de políticas públicas adequadas, Fava (2018) destaca ainda uma crítica que remete a resistência de alguns profissionais perante a esses novos paradigmas:

Os currículos atuais, em sua maioria, são construídos por especialistas com opiniões tendenciosas, previsíveis, almas ideológicas, pois desejam a manutenção dos padrões tradicionais e a preservação dos benefícios adquiridos. Em outros cenários, são leais às suas teses de estudos, tendo dificuldades de descartar partes de todo o tecido do conhecimento de seu campo, mesmo que estes já se encontrem desatualizados. (FAVA 2018, p. 144).

\section{A Educação à Distância}

De acordo com o Censo "EAD.BR" realizado entre 2017 e 2018, em seu relatório analítico da aprendizagem à distância no Brasil, o número total de matrículas registradas em cursos na modalidade EaD tem duplicado a cada ano, o que gerou um aumento de quase $1.400 \%$ nos últimos 10 anos.

Figura 1: Gráfico evolução de matrículas em cursos EaD. 


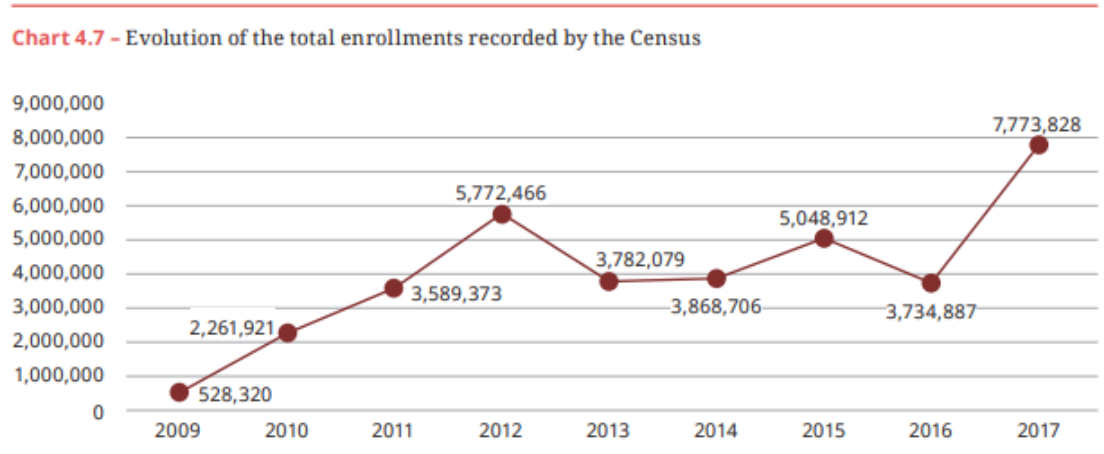

Fonte: ABED (2018).

Pode-se observar, portanto, que a EaD tem crescido substancialmente, favorecendo aos sistemas em inteligência artificial ganhar mais espaço nas plataformas que serão acessadas por cada vez mais usuários, tornando-as indispensáveis perante a este novo cenário educacional. Ou seja, a tendência é que a Educação à Distância, embora esteja sendo difundida apenas recentemente, impulsione o uso dos sistemas inteligentes, inclusive no ensino presencial.

\section{A inteligência artificial}

Inteligência Artificial ( $\mathrm{Al}$ em inglês ou IA em português) é a inteligência similar à humana exibida por mecanismos ou software. Os principais pesquisadores definem o campo como "o estudo e projeto de agentes inteligentes", onde um agente inteligente é um sistema que percebe seu ambiente e toma atitudes que maximizam suas chances de sucesso.

Ou seja, com o desenvolvimento dos computadores e dos processadores, houve a possibilidade de ampliar a inteligência humana, criando-se a Inteligência Artificial, que é conceituada de diversas maneiras pelos cientistas. Para Barr e Feigenbaum (1981, apud BARRETO; PREZOTO, 2010), "Inteligência Artificial é a parte da ciência da computação que compreende o projeto de sistemas computacionais que exibam características associadas, quando presentes no comportamento humano, à inteligência". Em suma, a IA é a forma de processar ou "pensar" informações de modo a produzir conclusões práticas, por meio de processamento de dados com maior quantidade, eficácia e velocidade.

\section{O uso da Inteligência Artificial no ensino}

No que se refere à plataforma de ensino a distância com tecnologia alimentada por base de dados e oferecendo a Inteligência Artificial como a principal ferramenta para busca e apresentação de aulas online, tem-se 0 
exemplo da Khan Academy, uma ONG que oferece aulas virtuais para os mais diversos conteúdos (ilustrada na Figura 2).

Figura 2: Site oficial da Khan Academy.

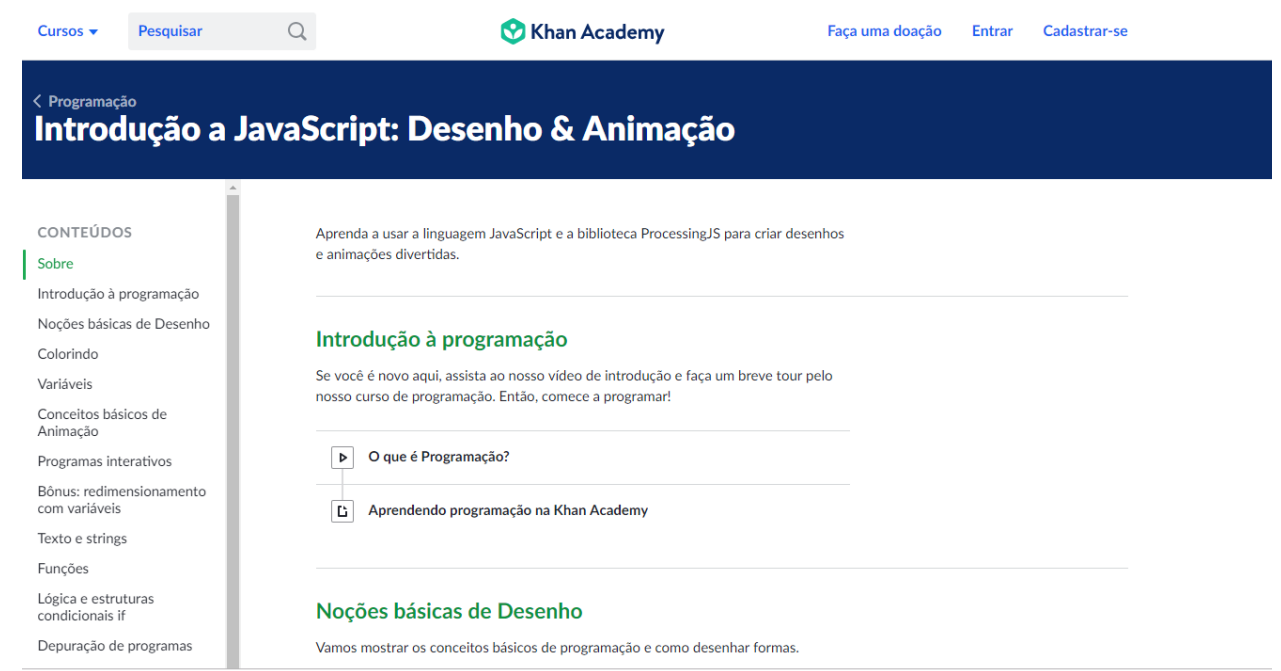

Fonte: https://pt.khanacademy.org/ (Acesso em: 13 mar. 2019).

No Brasil, Idoeta (2017) cita uma experiência em São Paulo, na qual o Centro Educacional SESI, em Arthur Alvim, disponibiliza aos seus alunos uma plataforma virtual para a realização de atividades diversas, com acompanhamento e feedback online. Além de outras características, este sistema realiza a verificação da aprendizagem por meio de algoritmos próprios, para que sejam indicadas ao aluno outras aulas e formas de estudo, conforme as dúvidas que ele apresenta.

Além dos exemplos supracitados, pode-se citar também a Altschool (Figura 3), na Califórnia, a Mindspark, na Índia (Figura 4,) e a Third place Learning, no Reino Unido (Figura 5).

$\mathrm{Na}$ Altschool, o aluno cria sua playlist de vídeos, exames e textos, de acordo com suas necessidades e preferências, aplicando-as em uma plataforma de ensino remota para interação contínua, adequada ao seu desenvolvimento.

Figura 3: Página web oficial da AltSchool. 


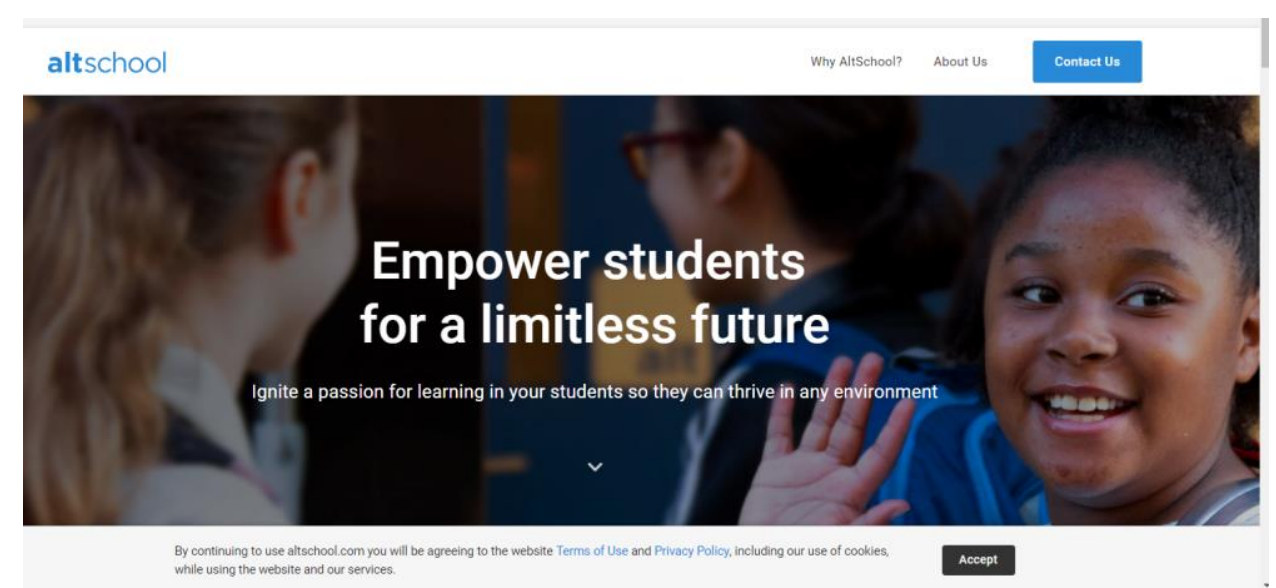

Fonte: https://www.altschool.com (Acesso em: 04 abr. 2019).

Além disso, na Mindspark, os professores podem identificar com exatidão, com o sistema $I A$, quais são as necessidades e carências de conteúdo de cada aluno, a partir de um banco de dados com milhões de visualizações, geradas durante anos de utilização da plataforma.

Figura 4: Página web oficial da Mindspark.

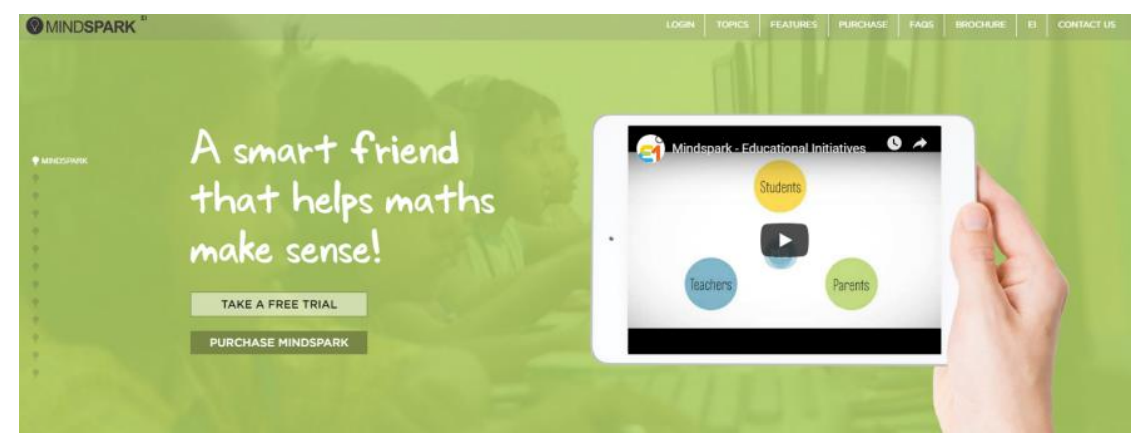

Fonte: https://mindspark.in/ (Acesso em: 04 abr. 2019).

Por sua vez, a Third Space Learning está em busca da melhoria da aprendizagem dos alunos em matemática com suporte pedagógico individualizado, baseando-se em dados colhidos de milhares de horas-aula previamente geradas e digitalizadas naturalmente.

Figura 5: Página web oficial da ThirdSpaceLearning. 


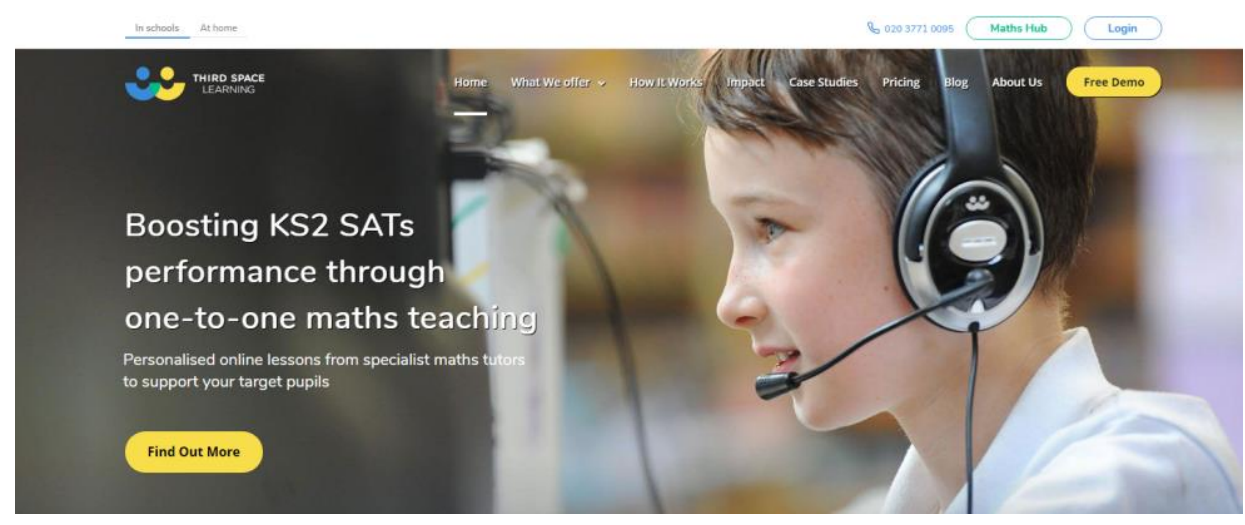

Fonte: https://thirdspacelearning.com/ (Acesso em: 04 abr. 2019).

Essas plataformas educacionais, baseadas em Inteligência Artificial, permitem que as instituições de ensino gradativamente possibilitem a construção de uma rede de tecnologia para capacitar e conectar famílias, alunos individuais, professores e outras escolas. Desse modo, elas oferecem ao estudante uma base de dados gigantesca e interativa. Esse sistema lógico, físico e complexo está em constante construção e mutação, pois oferece personalização na aprendizagem por meio da construção do perfil de cada estudante e da indicação de temas desejados para cada momento específico. Os programas de computadores que acessam estas plataformas de dados possibilitam infinitas interações com dados hipertextualizados.

Sendo assim, as informações de cada aluno são intercruzadas com as bases de dados da plataforma, trazendo os melhores resultados a partir de desenhos individualizados com base em aspectos pedagógicos, psicológicos, técnicos e éticos, para melhor aprendizagem personalizada. Destaca-se, porém, que o auxílio, o planejamento e a orientação docente continuam indispensáveis no processo de ensino aprendizagem, sendo proposta - como defendido por diversas correntes contemporâneas - apenas uma mudança de paradigma: o professor deixa de ser o centro do processo para dar este lugar ao aprendiz.

Estes modelos de ensino, por meio do acesso às informações digitais, podem colaborar com a atual educação em países como o Brasil, onde os alunos, às vezes, não possuem estrutura, currículo e qualidade satisfatória. Os estudantes podem ter um currículo pré-definido, mas a possiblidade de escolha sobre o que aprender e como fazer possibilita às pessoas ampliarem e personalizarem sua aprendizagem. Essa estratégia valoriza a aprendizagem autônoma, fator indispensável para a real aprendizagem, já que a alteração das estruturas cognitivas depende, em algum momento, da individualidade, conforme sugere Piazzi (2014), pois, como nos apresenta Glasser (2001 apud QUINTAS, p. 32): "[...] a boa educação é aquela em que o professor pede para que seus alunos pensem e se dediquem a promover um diálogo para promover a compreensão e o crescimento dos estudantes". 


\section{Desafios da formação docente e da educação nacional}

Uma das possibilidades para que a educação evolua da atual estrutura estagnada e apática de ensino é com a mudança dos agentes de interação entre aprendiz e conhecimento. Fato que não dispensa a importante figura do professor, apenas lhe impõe também a necessidade de atualização para lidar com os alunos das novas gerações. Para, Elizabeth Pinto; Ribeiro e Silveira apud Pinto (2005, p. 43):

[...] a postura do professor é um diferencial na tecnologia desenvolvida. Para tanto, é importante conhecer a IA, pois 0 desconhecimento pode ser "um instrumento para silenciar as manifestações da consciência política das massas, e muito particularmente das nações subdesenvolvidas" (apud PINTO, 2005).

Para Costa (2016) a educação requer uma formação de professores que seja capaz de dialogar com a tríade: Educação, Trabalho e Sociedade. Segundo essa autora:

A (re)construção dos saberes docentes é determinante na constituição da profissão professor, que se tece numa rede, que se desenha, a partir das crenças e ideologias referentes à sua concepção de mundo, sociedade, trabalho e educação, bem como do que se acredita ser função social da docência. (COSTA, 2016, p.19).

Não se tem notícias de mudanças significativas na educação no século XX na mesma grandeza em que se observou com a indústria e com outros setores da sociedade. Os professores permanecem diante dos alunos em sala de aula expondo suas narrativas e conteúdos pré-estabelecidos. Costa (2016, p. 98) afirma que "[...] é fundamental que ocorra uma ruptura com os modelos históricos de formação [...]" e lamenta que "[...] o Estado vem se omitindo na construção de políticas públicas educacionais que visem à superação do viés assistencialista, reducionista e emergencial presente na formação de professores" (COSTA, 2016, p. 96).

De acordo com os dados do censo mais recente, de 2018, das 181.939 escolas de educação básica, $28.673(15,8 \%)$ ofertam o ensino médio. Sendo assim, em relação à infraestrutura tecnológica, o relatório aponta que:

A disponibilidade de recursos tecnológicos (laboratório de informática, e internet banda larga) nas escolas de ensino médio é maior do que a observada para o ensino fundamental. Esses recursos são encontrados em mais de $60 \%$ das escolas, em todas as dependências administrativas. Bibliotecas ou salas 
de leitura estão presentes em mais de $80 \%$ de todas as dependências administrativas, passando de $90 \%$ nas redes federais e privadas. Enquanto o acesso à internet é uma realidade em $95,1 \%$ das escolas de ensino médio [...] (INEP, 2019, p. 1).

Insuficientemente, os laboratórios nestas escolas são constituídos por uma sala com média de 20 computadores (às vezes, com equipamentos de informática ultrapassados), alguns com o acesso à internet em torno de $2 \mathrm{Mbps}$. Esta realidade está distante do ideal, considerando a disponibilidade e o acesso democrático à informação.

A título de exemplo verificou-se in loco, as condições de dez escolas de educação básica (cinco estaduais e cinco federais) quanto a capacidade técnica para uso da tecnologia na educação. Os dados foram coletados com base no checklist visto no Quadro 1.

Quadro 1 - Verificação da estrutura escolar.

\section{Selecione apenas uma nota para cada item da sua escola Variando de "0" (totalmente insatisfatório) até "4" (totalmente satisfatório)}

Instruções:

Considere os itens disponíveis na sua escola a serem utilizados para as aulas ou a serem utilizados diretamente pelos próprios alunos.

Minha escola é: ( ) federal ( ) estadual ( ) municipal ( ) privada

\begin{tabular}{|c|c|c|c|c|}
\hline $\begin{array}{l}\text { Quanto a qualidade/atualização do(s) } \\
\text { laboratório(s) de informática }\end{array}$ & ( ) 0 & ( ) 2 & ( ) 3 & ( ) 4 \\
\hline $\begin{array}{l}\text { Quanto a disponibilidade de uso e horários, } \\
\text { para os alunos, do(s) laboratório(s) de } \\
\text { informática }\end{array}$ & ( ) 0 & ( )2 & ( ) 3 & ( ) 4 \\
\hline $\begin{array}{l}\text { Quanto a existência/qualidade de servidor } \\
\text { próprio para hospedagem de sistemas } \\
\text { informatizados }\end{array}$ & ( ) 0 & ( )2 & ( ) 3 & ( ) 4 \\
\hline $\begin{array}{l}\text { Quanto a disponibilidade de projetor(es) } \\
\text { multimídia }\end{array}$ & ( ) 0 & ( )2 & ( ) 3 & ( ) 4 \\
\hline $\begin{array}{l}\text { Quanto a disponibilidade de sistema(s) de } \\
\text { som }\end{array}$ & ( ) 0 & ( )2 & ( ) 3 & ( ) 4 \\
\hline $\begin{array}{l}\text { Quanto a disponibilidade de equipamento(s) } \\
\text { de foto e/ou filmagem }\end{array}$ & ( ) 0 & ( )2 & ( ) 3 & ( ) 4 \\
\hline $\begin{array}{l}\text { Quanto a disponibilidade de Internet (rede a } \\
\text { cabo) de alta velocidade }\end{array}$ & ( ) 0 & ( )2 & ( ) 3 & ( ) 4 \\
\hline $\begin{array}{l}\text { Quanto a disponibilidade de Internet (rede } \\
\text { sem fio) de alta velocidade }\end{array}$ & ( ) 0 & ( )2 & ( ) 3 & ( ) 4 \\
\hline $\begin{array}{l}\text { Quanto a disponibilidade de software, } \\
\text { simuladores ou afins adquiridos para o } \\
\text { ensino }\end{array}$ & ( ) 0 & ( )2 & ( ) 3 & ( ) 4 \\
\hline
\end{tabular}




\begin{tabular}{|l|l|llllll|}
\hline $\begin{array}{l}\text { Quanto a disponibilidade de técnico(s) ou } \\
\text { especialista(s) ( ( ) } 0\end{array}$ & ( ) 1 & ( ) 2 & ( ) 3 & ( ) 4 \\
\hline $\begin{array}{l}\text { Quanto para para suporte de TI } \\
\text { capacitação para professores no uso de } \\
\text { tecnologias educacionais }\end{array}$ & & & & & & \\
\hline $\begin{array}{l}\text { Quanto as experiências ou cursos ou testes } \\
\text { institucionais já implementados de uso da } \\
\text { tecnologia no ensino }\end{array}$ & & & & ( ) 1 & ( ) 2 & ( ) 3 & ( ) 4 \\
\hline
\end{tabular}

Fonte: dados da pesquisa.

Neste estudo, admitiu-se a escala de análise vista no Quadro 2.

Quadro 2 - Cômputo para atribuição de conceito.

\begin{tabular}{|l|l|}
\hline Somatória menor que 24 pontos & $\begin{array}{l}\text { Condições insuficientes para o uso da } \\
\text { tecnologia na educação. }\end{array}$ \\
\hline Somatória entre 24 e 33 pontos & $\begin{array}{l}\text { Condições propícias para o uso da tecnologia } \\
\text { na educação. }\end{array}$ \\
\hline Somatória maior que 33 pontos & $\begin{array}{l}\text { Condições ótimas para o uso da tecnologia na } \\
\text { educação }\end{array}$ \\
\hline
\end{tabular}

Fonte: dados da pesquisa.

Os resultados coletados podem ser observados no Quadro 3.

Quadro 3 - Resultados da estrutura escolar.

\begin{tabular}{|c|c|c|c|}
\hline Escola & Esfera & Pontuação obtida & Escala \\
\hline 1 & Estadual & 15 & Insuficiente \\
\hline 2 & Estadual & 40 & Ótima \\
\hline 3 & Estadual & 15 & Insuficiente \\
\hline 4 & Estadual & 18 & Insuficiente \\
\hline 5 & Estadual & 19 & Insuficiente \\
\hline 6 & Federal & 33 & Ótima \\
\hline 7 & Federal & 40 & Ótima \\
\hline 8 & Federal & 35 & Ótima \\
\hline 9 & Federal & 10 & Insuficiente \\
\hline 10 & Federal & 43 & Ótima \\
\hline
\end{tabular}

Fonte: dados da pesquisa.

Observou-se que das cinco escolas estaduais, quatro apresentaram condições "insuficientes" e apenas uma "ótima". No outro oposto, das cinco escolas federais, quatro apresentaram condições "ótimas" e apenas uma "insuficiente".

O fato de existirem condições ótimas, por si só, não significa que a escola já utiliza a tecnologia a seu favor, porém, demonstra que potencialmente tem todas as condições necessárias. O resultado, em especial das escolas estaduais, mostra que a defasagem de tecnologia depende do poder público 
para ampliação da comunicação de dados e da infraestrutura. Caso contrário, todas estas possibilidades aqui vislumbradas continuarão na espera para que de fato sejam implementadas com sucesso.

\section{Considerações finais}

A inteligência artificial está em nossas vidas há alguns anos por meio da execução de atividades financeiras, profissionais e pessoais em smartphones conectados à internet, por exemplo. Na educação não é diferente. Grandes empresas já se articularam para operar neste seguimento de mercado, da mesma forma que em outros seguimentos. Mesmo assim, cabe à sociedade, ao poder público e aos especialistas da área buscar alternativas políticas, pedagógicas, éticas e sociais para maximizar o uso desta tecnologia com fins produtivos. Desse modo, será facilitado o acesso ao conhecimento para todos, inclusive àqueles com dificuldades físicas para chegar às pessoas e instituições de ensino de qualidade, possibilitando uma emancipação distribuída do conhecimento por meio da educação à distância, através das plataformas com sistemas de Inteligência Artificial.

\section{Referências}

ABED. Censo EAD.BR: relatório analítico de aprendizagem a distância no Brasil 2018. [livro eletrônico] / [organização] ABED - Associação Brasileira de Educação a Distância; [traduzido por Maria Thereza Moss de Abreu]. Curitiba: InterSaberes, 2018. Disponível em: <http://abed.org.br/arquivos/CENSO EAD BR 2018 digital complet o.pdf>. Acesso em: $21 \mathrm{abr} .2019$.

BARRETO, L. R.; PREZOTO, M. G. Introdução a sistemas especialistas. 2010. 34f. Relatório (Disciplina de Mestrado em Tecnologia para Sistemas e Fenômenos Complexos) - Faculdade de Tecnologia de Limeira, Limeira, 2010.

BRASIL. Decreto no 9.057 de 25 de maio de 2017. Regulamenta o art. 80 da Lei $n^{\circ}$ 9.394, de 20 de dezembro de 1996, que estabelece as diretrizes e bases da educação nacional. Planalto, Brasília-DF, 2017. Disponível em: <http://www.planalto.gov.br/ccivil 03/ Ato2015-2018/2017/Decreto/D9057.htm> Acesso em: 11 abr. 2019.

\section{COSTA, Maria Adélia da. Políticas de Formação Docente para Educação}

Profissional: realidade ou utopia? Curitiba: Appris, 2016.

FAVA, Rui. Trabalho Educação e Inteligência Artificial: a era do indivíduo versátil. Porto Alegre: Editora Penso, 2018.

IDOETA, Paula A. Como a Inteligência Artificial já está mudando salas de aula no Brasil e no mundo. BBC Brasil, São Paulo, 25 de agosto de 2017. Disponível em: <https://www.bbc.com/portuguese/geral-40969450> Acesso em: 11 abr. 2019.

INEP. INSTITUTO NACIONAL DE ESTUDOS E PESQUISASA EDUCACIONAIS.

Dados do censo escolar. Disponível em: <http://portal.inep.gov.br/artigo/- 
/asset_publisher/B4AQV9zFY7Bv/content/dados-do-censo-escolar-noventa-e-cincopor-cento-das-escolas-de-ensino-medio-tem-acesso-a-internet-mas-apenas-44-temlaboratorio-de-ciencias/21206>. Acesso em: 26 abri. 2019.

QUINTAS, M. J. M. Aprendizagem colaborativa da eletricidade com ensino interativo. 2017. 424f. Tese (Doutorado em Ensino e Divulgação das Ciências) Universidade do Porto, Porto, 2017. Disponível em:

$<$ https://sigarra.up.pt/fcup/pt/pub geral.show file?pi doc id=97143>. Acesso em: 26 abr. 2019.

PIAZZI, Pierluigi. Aprendendo inteligência. São Paulo: Aleph, 2014.

PINTO, Elizabeth Maria; RIBEIRO, Giuliano Richards; SILVEIRA, Antônio Claudio Jorge da. Inteligência artificial na educação profissional técnica de nível médio: desafios da prática docente em escola pública. In: COSTA, Maria Adélia da (org.) Educação Profissional. Goiânia: Espaço Acadêmico, 2018.

XAVIER, Antônio Carlos. Educação tecnológica e inovação: desafio da aprendizagem hipertextualizada na escola contemporânea. Revista (Con) Textos Linguísticos. Espírito Santo: UFES, vol. 7, no 8.1, 2013. Disponível em: <http://periodicos.ufes.br /contextoslinguisticos/article/view/6004>. Acesso em: 21 abr. 2019. 